\title{
Sex Identification Based on Tooth Crown Trait Analysis Among the Mongoloid Race
}

\author{
Syifa Ahliya ${ }^{1}$, Bambang Tri Hartomo ${ }^{2}(\mathbb{0}$, Angger Waspodo Dias Adrianto²®, Agoeng Tjahajani \\ Sarwono $^{3}$ (D), Elza Ibrahim Auerkaris ${ }^{3}$
}

${ }^{1}$ Undergraduate Program, Faculty of Dentistry, Universitas Indonesia, Jakarta, Indonesia.

2Dentistry Master Program, Faculty of Dentistry, Universitas Indonesia, Jakarta, Indonesia.

${ }^{3}$ Department of Oral Biology, Faculty of Dentistry, Universitas Indonesia, Jakarta, Indonesia.

Author to whom correspondence should be addressed: Elza Ibrahim Auerkari, Department of Oral Biology, Faculty of Dentistry, Universitas Indonesia, Salemba Raya 4, Jakarta 0430, Indonesia. Phone: +6221 3911502. E-mail: elza.ibrahim@ui.ac.id.

Academic Editor: Alessandro Leite Cavalcanti

Received: 07 March 2020 / Accepted: 18 June 2020 / Published: 08 July 2020

How to cite this article: Ahliya S, Hartomo BT, Adrianto AWD, Sarwono AT, Auerkari EI. Sex identification based on tooth crown trait analysis among the Mongoloid race. Pesqui Bras Odontopediatria Clín Integr. 2020; $20: e 5681$. https://doi.org/10.1590/pboci.2020.129

\begin{abstract}
Objective: To determine whether anterior and posterior tooth crown traits exhibit sexual dimorphism and identify traits characteristic to the Mongoloid race, especially among the Indonesian population. Material and Methods: This study cross-sectional study analyzed 108 dental casts from 36 males and 72 females. The traits analyzed included winging, shoveling, double shoveling, canine mesial ridge, canine distal accessory ridge, hypocone, metaconule, Carabelli's cusp, protostylid, metaconulid, enteconulid, and hypoconulid. All tooth crown traits were scored based on the ASUDAS scoring system. Descriptive statistics were used to calculate the absolute and relative frequencies. The Chi-square tests was used to determine significant differences in anterior and posterior tooth crown traits between males and females. Level of significance was set at $5 \%$. Results: None of the traits showed sexual dimorphism. Moreover, the most common traits among the Mongoloid race were hypocone (94.4\%) and shoveling (86.1\%). Conclusion: Although none of the traits exhibited sexual dimorphism, most of them had a higher incidence among females than males. Nonetheless, further research including adequate samples and a similar number of females and males, is needed, especially for population studies.
\end{abstract}

Keywords: Forensic Dentistry; Forensic Anthropology; Tooth; Dental Casting Technique. 


\section{Introduction}

Recent mass fatalities due to natural or man-made disasters still remain a considerable problem. Moreover, such disasters have resulted in a significant number of unidentified victims, the identification of whom has become an important area of investigation. Accordingly, the identification process involves establishing biological profiles, such as age, sex, stature, and race [1,2]. Sex has generally been the first individual component to be analyzed given that other biological profiles, like age and stature, depend on sex determination. Like most other primates, humans exhibit differing morphological patterns between males and females, which is called sexual dimorphism [3].

The field of forensic dentistry utilizes several bodily components, including the jaw bone, saliva, bite patterns, lip patterns, rugae palatina, processus coronoideus, and teeth [4-7], for forensic identification. During the past decade, considerable research has been conducted on the teeth as a means of establishing a biological profile. Human teeth have been considered one of the reliable bodily components that can be used for identifying individuals who, due to disasters or other injuries, can no longer be identified. The teeth are composed of calcified biological material that is hard, stable, and able to withstand environmental changes [8], making them suitable for forensic identification. The morphology of both anterior and posterior teeth is rather unique with some varying characteristics [9].

In fact, the Arizona State University Dental Anthropology System (ASUDAS) has described several morphological dental characteristics, a project that had been initiated by Christy Turner II in 1970 and continue by G. Richard Scott and Christian R. Nichol in 1991. The aforementioned project aimed to standardize graded guidelines that other studies worldwide can compare their scoring system [3,9]. Some of the morphological characteristics introduced by Turner and Scott include winging, shoveling, double shoveling, canine mesial ridge, canine distal accessory ridge, hypocone, metaconule, and Carabelli’s cusp for anterior teeth and protostylid, metaconulid, enteconulid, and hypoconulid for posterior teeth.

Previous research involving the frequency of nonmetric traits among a Brazilian sample showed that Carabelli's cusp exhibited sexual dimorphism given is a higher incidence among males (27.1\%) than females (12.3\%) [3]. Another study revealed that females had significantly greater double shoveling and shoveling grades than males [10]. Besides showing sexual dimorphism, tooth crown traits can also be used as a marker for certain populations. Accordingly, shoveling has been most frequently observed among Mongoloid groups, especially Asian populations, while Carabelli's cusp has been most commonly detected among Caucasoid groups, especially European populations [11].

The present study aimed to determine whether anterior and posterior tooth morphological characteristics exhibit sexual dimorphism and identify tooth morphological characteristics among the Mongoloid race, especially in the Indonesian population.

\section{Material and Methods}

\section{Study Design and Sample}

This cross-sectional study included 108 dental casts from 36 males and 72 females. Only dental casts with complete data, such as sex (male and female), age (12-60 years old), and race, were included. Moreover, dental casts had to include a complete set of teeth with an intact crown, especially for the upper incisors, upper canines, and upper and lower molars. 
The dental casts were collected from the Department of Prosthodontics, Faculty of Dentistry, University of Indonesia. The traits analyzed included winging (upper central incisor), shoveling (upper right central incisor), double shoveling (upper right central incisor), canine mesial ridge (upper right canine), canine distal accessory ridge (upper right canine), hypocone (upper right molar), metaconule (upper right molar), Carabelli's cusp (upper right molar), protostylid (lower right molar), metaconulid (lower right molar), enteconulid (lower right molar), and hypoconulid (lower right molar). All tooth crown traits were scored based on the ASUDAS scoring system.

The measurements were carried out by three observers independently. From the dental casts that were collected for the study, 20 samples were taken for conformity testing to prove the reliability and validity of the measurements. First, the observers' perceptions were synchronized to apply the same scoring system used in similarly perception, so that the scoring system used is appropriate and has the same understanding. Then, several exercises were carried out to equalize the data collection process. The outcome was subjected to intra- and inter- observer Kappa testing which showed a good match between measurements tested. The interobserver suitability test for the measurement of 20 samples showed no significant difference in the subjectivity of the measurement $(p=0.653)$ with a conformity value of 0.871 .

Data Analysis

Data were analyzed using IBM SPSS Statistics for Windows Software, version 20 (IBM Corp., Armonk, NY, USA). Descriptive statistics were used to calculate the absolute and relative frequencies. The Chi-square tests was used to determine significant differences in anterior and posterior tooth crown traits between males and females. Level of significance was set at $5 \%$.

\section{Ethical Considerations}

This research project was approved by the Ethics Research Committee of the Faculty of Dentistry, Universitas Indonesia (Protocol No. 090620619; 101 / Ethical Approval/FKGUI/VIII/2009).

\section{Results}

The analysis showed that all of the traits were higher among females. However, no significant difference in each trait was observed between both sexes. The trait most common among the Mongoloid race was hypocone $(94.4 \%)$ followed by shoveling (86.1\%), whereas the least common trait was metaconule $(4.6 \%)$, followed by Carabelli’s cusp (14.8\%) (Table 1$)$.

Table 1. Anterior and posterior tooth crown trait scoring.

\begin{tabular}{|c|c|c|c|c|c|}
\hline \multirow[b]{2}{*}{ Traits } & \multicolumn{2}{|c|}{ Sex } & \multirow[t]{2}{*}{$\mathbf{N}$} & \multirow{2}{*}{$\begin{array}{c}\text { Percentage } \\
\text { of Traits }\end{array}$} & \multirow[t]{2}{*}{ p-value } \\
\hline & $\begin{array}{l}\text { Male } \\
\mathrm{N}(\%)\end{array}$ & $\begin{array}{c}\text { Female } \\
\text { N (\%) }\end{array}$ & & & \\
\hline Winging & $11(28.9)$ & $27(71.1)$ & 38 & 35.2 & 0.618 \\
\hline Shoveling & $31(33.3)$ & $62(66.7)$ & 93 & 86.1 & 1.000 \\
\hline Double Shoveling & $28(36.8)$ & $48(63.2)$ & 76 & 70.4 & 0.333 \\
\hline Canine Mesial Ridge & $11(35.5)$ & $20(64.5)$ & 31 & 28.7 & 0.940 \\
\hline Canine Distal Accessory Ridge & $12(30.8)$ & $27(69.2)$ & 39 & 36.1 & 0.832 \\
\hline Hypocone & $35(34.3)$ & $67(65.7)$ & 102 & 94.4 & 0.661 \\
\hline Metaconule & $2(40.0)$ & $3(60.0)$ & 5 & 4.6 & 1.000 \\
\hline Carabelli’s Cusp & $4(25.0)$ & $12(75.0)$ & 16 & 14.8 & 0.632 \\
\hline Protostylid & $9(39.1)$ & $14(60.9)$ & 23 & 21.3 & 0.678 \\
\hline
\end{tabular}




\begin{tabular}{lccccc} 
Hypoconulid & $30(31.9)$ & $64(68.1)$ & 94 & 87.0 & 0.544 \\
Enteconulid & $12(46.2)$ & $14(53.8)$ & 26 & 24.1 & 0.176 \\
Metaconulid & $6(25.0)$ & $18(75.0)$ & 24 & 22.2 & 0.461 \\
\hline
\end{tabular}

\section{Discussion}

The present study scored anterior and posterior tooth crown traits based on guidelines established by the ASUDAS, with the breakdown of each trait presented in the following paragraphs.

Although no sexual dimorphism has been observed for winging, its incidence was higher among females than males. Among the study population, 35.2\% exhibit winging. It was revealed moderate frequencies of winging among the East and Central Asian, American Arctic, and Sunda-Pacific populations [12], with the Northeast Siberian and North and South American populations having the highest frequencies of winging $[13]$.

The present study found no sexual dimorphism for shoveling, althea its incidence was higher among females $(66.7 \%)$ than males (33.3\%). Similarly, previous studies on shoveling have shown no sexual dimorphism for this trait [12]. Research carried out with Asian individuals revealed that females had a significantly greater shoveling grade than males [10], a finding consistent with that presented herein where females had higher incidences of shoveling than males. Moreover, the frequency of shoveling among the Indonesian population had been found to be rather high (86.1\%) [13] published the Asian population dental complex termed "Mongoloid Dental Complex." Accordingly, one characteristic of this complex was the high frequency of shovel-shaped upper incisors [14].

Although no sexual dimorphism had been found for double shoveling, its incidence was higher among females $(63.2 \%)$ than males $(36.8 \%)$. A previous study revealed that females had a significantly greater double shoveling grade than males [10]. Meanwhile, Turner who studied the broad Mongoloid dental complex, showed that double shoveling was more frequent than single shoveling in the Sinodont dental complex (one division of the Mongoloid dental complex) [14].

The Mongoloid race had been found to have a low frequency of canine mesial ridge (Bushmen Canine) (28.7\%), a trait first observed in 1975. This condition occurred when a strongly developed mesiolingual marginal ridge of the upper canine fused with the tuberculum dentale. The term "Bushman canine" was established due to its high occurrence among the Bushmen and other Sub-Saharan African groups, suggesting that this is one of the characteristic traits of the Negroid race [13].

The present study found no sexual dimorphism for canine distal accessory ridge, a result inconsistent with that revealed by previous author [12]. Canine distal accessory ridge was the most sexually dimorphic crown trait, with males exhibiting higher expression and frequencies [13]. Similarly, although the present study found no sexual dimorphism for Carabelli's cusp, the Brazilian study's found that Carabelli's cusp did show sexual dimorphism [3]. However, Hanihara observed no significant sexual dimorphism for Carabelli’s cusp in either the frequency or expression of the structure [3]. The incidence of Carabelli's cusp among the Indonesian population, one of Mongoloid races, is rather low with (14.8\%). Moreover, Scott and Turner demonstrated that this trait has long been associated with Western Eurasian (Caucasoid) populations and occurs less frequently in other populations. Finally, our results found no sexual dimorphism for protostylid, hyopconulid, enteconulid, and metaconulid [13].

One major limitation of the present study was the availability of samples. Dental casts were inadequate for population studies. The data presented herein showed that no traits exhibited sexual 
dimorphism, perhaps due to the unidentical number of female and male samples. Thus, future studies should include a similar number of female and male samples are required to establish more precise conclusions. However, the teeth remain an essential component for identifying individuals considering their resistance to environmental changes and can be a key component for population studies.

\section{Conclusion}

Although none of the traits exhibited sexual dimorphism, most of them had a higher incidence among females than males. Nonetheless, further research, including adequate samples and a similar number of females and males, is needed, especially for population studies.

\section{Authors' Contributions}

\begin{tabular}{|c|c|c|}
\hline SA & (iD) $0000-0001-8245-058 \mathrm{X}$ & Investigation, Formal Analysis and Writing - Original Draft Preparation. \\
\hline $\mathrm{BTH}$ & (iD) $0000-0003-3902-7780$ & Conceptualization, Methodology and Writing - Review and Editing. \\
\hline AWDA & (iD) $0000-0001-9006-7177$ & Investigation and Writing - Original Draft Preparation. \\
\hline ATS & (iD) $0000-0002-1066-9221$ & Conceptualization, Methodology and Writing - Review and Editing. \\
\hline EIA & (iD) $0000-0002-5680-7925$ & Conceptualization, Methodology and Writing - Review and Editing. \\
\hline
\end{tabular}

\section{Financial Support}

Universitas Indonesia Research Grant (Hibah PUTI 2020), Grant No. NKB-2334/UN2.RST/HKP.05.00/2020.

\section{Conflict of Interest}

The authors declare no conflicts of interest.

\section{References}

[1] Wiersema JM. Evolution of forensic anthropological methods of identification. Acad Forensic Pathol 2016; 6(3):3619. https://doi.org/10.23907/2016.038

[2] Hartomo BT, Adrianto AWD, Anas AN, Basman RS, Auerkari EI. The use of human intercanine and intermolar for determining sex on natural disaster. AIP Conference Proceedings 2019; 2019:040020. https://doi.org/10.1063/1.5096753

[3] Tinoco RLR, Lima LNC, Delwing F, Francesquini Jr L, Daruge Jr E. Dental anthropology of a Brazilian sample: frequency of nonmetric traits. Forensic Sci Int 2016; 258:102.e1-102.e5. https://doi.org/10.1016/j.forsciint.2015.10.019

[4] Bima TRAH, Adji RS, Auerkari EI. Early Detection of bacillus anthracis from saliva in anticipation of a bioterrorism attack. Pesqui Bras Odontopediatria Clín Integr 2019; 19:e4873. https://doi.org/10.4034/PBOCI.2019.191.84

[5] Suhartono AW, Syafitri K, Puspita AD, Soedarsono N, Gultom FP, Widodo PT, et al. Palatal rugae patterning in a modern Indonesian population. Int J Legal Med 2016; 130(3):881-7. https://doi.org/10.1007/s00414-015-1272-5

[6] Luthfi M, Suhartono AW, Puspita AD, Auerkari EI. Third molar development age range on Indonesian population from various ethnics based on radiograph findings: a preliminary study. J Int Dent Med Res 2017; 10(2):299-302.

[7] Basman RS, Puspita AD, Achmad RT, Suhartono AW, Auerkari EI. Palatal rugae comparison between ethnic Javanese and non-Javanese. J Phys: Conf Series 2018; 1025(1):012046.

https://doi.org/10.1088/1742-6596/1025/1/012046

[8] Apriyono DK. Metode penentuan usia melalui gigi dalam proses identifikasi korban. CDK J 2016; 43(1):71-4. [In Indonesian].

[9] Marado LM. Dental nonmetric trait intraobserver precision: three observations of a large sample. Anthropol Anz 2017; 74(1):15-23. https://doi.org/10.1127/anthranz/2017/0686

[10] Kimura R, Yamaguchi T, Takeda M, Kondo O, Toma T, Haneji K, et al. A common variation in EDAR is a genetic determinant of shovel-shaped incisors. Am J Hum Genet 2009; 85(4):528-35. https://doi.org/10.1016/j.ajhg.2009.09.006

[11] Chrysostomou P, Thompson TJU. Anthropology: Ancestry Assessment. In: Payne-James J, Byard RW. Encyclopedia of Forensic and Legal Medicine. 2nd. ed. London: Elsevier; 2015. 
[12] Turner II CG, Nichol CR, Scott GR. Scoring procedures for key morphological traits of the permanent dentition: The Arizona State University dental anthropology system. Adv Dent Anthropol 1991;13-31.

[13] Haddow SD. Dental morphological analysis of Roman Era Burials from the Dakhleh Oasis, Egypt. [Thesis]. London: University College London - Institute of Archaeology; 2012.

[14] Pilloud MA, Edgar HJH, George R, Scott GR. Dental morphology in biodistance analysis. In: Pilloud MA, Hefner JT. Biological Distance Analysis: Forensic and Bioarchaeological Perspectives. London: Elsevier Inc.; 2016. p. 109133. https://doi.org/10.1016/B978-0-12-801966-5.00006-8 